\title{
ENSINO REMOTO EMERGENCIAL: O CASO DO CURSO DE ENGENHARIA DE ALIMENTOS DA UNIVERSIDADE FEDERAL DE MINAS GERAIS
}

DOI: 10.37702/2175-957X.COBENGE.2021.3642

William James Nogueira Lima - wjnlima@ufmg.br

Universidade Federal de Minas Gerais

Rua Basílio de Paula 47

39400-145 - MONTES CLAROS - MG

Jardel Batista Soares - jardelhist@yahoo.com.br

Universidade Federal de Minas Gerais

Rua Neco de Santa Maria 1104

39403-212 - Montes Claros - MG

Renato Dourado Maia - rdmaia@ufmg.br

Universidade Federal de Minas Gerais

Rua Laura Prates 985

39402-207 - Montes Claros - MG

Resumo: No contexto da pandemia da Covid-19, o Ensino Remoto Emergencial (ERE) apresentou-se como uma possibilidade concreta para garantir a continuidade do processo ensino-aprendizagem dos estudantes dos cursos de graduação da UFMG. A suspensão temporária de aulas presenciais nas universidades foi adotada com o objetivo de mitigar a propagação do coronavírus e reduzir o risco de contágio e proliferação entre professores e estudantes. Este trabalho apresenta a experiência do Colegiado do curso de Engenharia de Alimentos na adaptação do ensino presencial ao ensino remoto emergencial, desde o planejamento, a adaptação dos planos de ensino das disciplinas ao Ensino Emergencial Remoto e a sua implementação. Uma pesquisa de avaliação da implementação do ERE foi feita para a avaliação das diferentes atividades no curso.

Palavras-chave: Ensino Remoto Emergencial, Pandemia, Gestão, Diagnostico 


\section{ENSINO REMOTO EMERGENCIAL: O CASO DO CURSO DE ENGENHARIA DE ALIMENTOS DA UNIVERSIDADE FEDERAL DE MINAS GERAIS}

\section{INTRODUÇÃO}

Em 11 de março de 2020, a Organização Mundial da Saúde (OMS) declarou a pandemia do coronavírus SARS-COV-2 (Covid-19). A estratégia mais eficiente para a redução da contaminação pelo vírus demonstrou-se ser o isolamento social, de modo que, na semana seguinte, as atividades acadêmicas presenciais na Universidade Federal de Minas Gerais foram suspensas.

A Portaria 343 de 17 de março de 2020 do Ministério da Educação do Brasil (BRASIL, 2020) autorizou a substituição das aulas presenciais nas instituições de ensino superior do país por aulas que utilizem meios e tecnologias de informação e comunicação. De maneira geral, a portaria incentivou que as atividades acadêmicas presenciais pudessem ser realizadas de forma remota e excepcional, aplicando o Ensino Remoto Emergencial com apoio de plataforma e tecnologia digitais.

A suspensão das atividades acadêmicas presenciais obrigou docentes e discentes a transferirem e transporem metodologias e práticas pedagógicas típicas dos domínios físicos de aprendizagem para a realidade on-line, instituindo o termo Ensino Remoto Emergencial (ARRUDA, 2020; BARBOSA et al., 2020).

A utilização da tecnologia de informação no Ensino Remoto Emergencial favoreceu o surgimento de novas formas de conexão e métodos de avaliação do processo de ensino e aprendizagem, tais como avaliação de trabalhos de cooperação ou de registro individual de resultados, formas variadas de entrega e apresentação do conteúdo programático utilizando recursos diversos. Ferramentas digitais, próprias do universo empresarial, foram adaptadas ao ambiente acadêmico, como, por exemplo: Microsoft Teams, Google Meet, Zoom, Hangouts, Duo, entre outras. Essa mudança na relação ensino-aprendizagem deve, necessariamente, ser acompanhada da certeza do acesso por todos os alunos e professores a condições básicas de infraestrutura e acesso à rede internacional de computadores (internet).

A maioria das instituições de ensino superior, segundo Arruda (2020), utilizou estratégias de ensino remoto, de modo que as aulas fossem transmitidas por web conferência em tempo real, permitindo aos discentes reproduzir parcialmente as interações e reproduzir a organização do tempo de aprendizagem de forma mais semelhante ao ensino presencial. A transição do ensino presencial para o Ensino Remoto Emergencial, na maioria das instituições, ocorreu de modo não desenhado previamente, sendo permeado por dúvidas sobre a concepção do ambiente virtual de ensino e aprendizagem, dentre as quais se podem destacar a escolha da forma de comunicação entre docentes e discentes, a definição o sistema de avaliação do aprendizado e sua aplicação, as estratégias de alternância das formas de comunicação e de adaptação das atividades dirigidas.

A Universidade Federal de Minas Gerais, preocupada em garantir a qualidade do ensino remoto a ser ofertado de forma emergencial, realizou intensa discussão entre a comunidade acadêmica que culminou na elaboração do documento "Ensino Remoto Emergencial (ERE) nos cursos de graduação da UFMG (UFMG, 2020).

Durante essa discussão o Colegiado do curso de Engenharia de Alimentos, com apoio do Núcleo Docente Estruturante, realizou pesquisa para identificar as principais dificuldades a serem enfrentadas pela comunidade acadêmica durante a implantação e reali- 
zação do ERE. O resultado dessa pesquisa balizou ações de adaptação das atividades acadêmicas ao ERE no curso de Engenharia de Alimentos.

\section{OBJETIVO}

Este artigo objetiva apresentar a experiência do Colegiado do curso de Engenharia de Alimentos na adaptação do ensino presencial ao Ensino Remoto Emergencial, desde o planejamento e adaptação dos planos de ensino das disciplinas até a sua execução. Ao final do período letivo de $2020 / 1$ foi avaliado o resultado das ações junto ao desempenho acadêmico dos discentes.

\section{ENSINO REMOTO EMERGENCIAL}

No contexto da pandemia da Covid-19, o Ensino Remoto Emergencial (ERE) apresenta-se como uma possibilidade concreta para garantir a continuidade do processo ensino-aprendizagem dos estudantes do curso de Engenharia de Alimentos da UFMG sem a interação física entre docentes e discentes.

Essa solução temporária necessita da garantia dos meios e das condições materiais para implementação da proposta, bem como demanda reflexões sobre os processos pedagógicos que constituem as práticas de ensino e de avaliação nas diferentes atividades acadêmicas. Ademais, envolve, naturalmente, a utilização de soluções de ensino totalmente remotas para instrução ou educação que, de outra forma, seriam ministradas presencialmente ou como cursos combinados ou híbridos, e que retornarão a esse formato assim que a crise ou emergência diminuir (HODGES et al, 2020).

O uso das Tecnologias Digitais de Informação e Comunicação (TDICs) é fundamental para realizar a interação virtual entre docentes e estudantes e consolidar o processo de ensino-aprendizagem no Ensino Remoto Emergencial.

É premissa que o processo de ensino-aprendizagem a ser desenvolvido pelos docentes deva estar amparado institucionalmente por condições que garantam acesso dos estudantes às tecnologias digitais e conexão à Internet, apoio para acessibilidade e inclusão dos estudantes com deficiência, acesso pelos docentes às plataformas virtuais e a orientações para a sua utilização no ensino, entre outros aspectos.

Os docentes devem estar capacitados e esclarecidos sobre os diferentes conceitos existentes no âmbito das metodologias e estratégias de ensino para otimizar o processo de ensino-aprendizagem, bem como desenvolver habilidades para interagir com as tecnologias digitais da informação e comunicação (TDIC) disponibilizadas atualmente. $\mathrm{O}$ Quadro 1adaptado de MOREIRA E SCHLEMMER (2020), apresenta um resumo das metodologias e estratégias de ensino mediado por tecnologias digitais de informação e comunicação.

A interação no ensino digital pode acontecer entre aluno-conteúdo, alunotutor/professor ou aluno-aluno, sendo mediadas por computador ou outro equipamento. As estratégias para essas interações podem ser síncronas, ou seja, em tempo real, ou podem ser assíncronas, em tempo não-real, de modo que a comunicação não acontece de forma simultânea, flexibilizando o acesso à informação pelo discente (MANTOVANI, 2013).

Relatos de alguns docentes que já lecionaram no Ensino Remoto Emergencial apontam observações recorrentes tais como: i) não ser viável apenas transpor a aula presencial para o modelo a distância/remoto; ii) o tempo para aprendizado no ERE é mais lento do que no ensino presencial; iii) o ERE pode ser profundamente desgastante para o estudante, sendo relatadas dificuldades para o encontro de ambiente doméstico que 
favoreça a aprendizagem; iv) o excesso de atividades síncronas decorrentes de diversas atividades acadêmicas curriculares cursadas pelo estudante piora o desempenho acadêmico; v) são frequentes as referências de cansaço ou fadiga "Zoom fatigue"; vi) redução da duração da aula expositiva e videoaulas para até 20 minutos e de diálogos para até no máximo 50 minutos para favorecer a atenção; e vii) a estratégia síncrona deve ser utilizada prioritariamente para discussão e esclarecimento de dúvidas, UFMG (2020).

Quadro 1 - Metodologias e estratégias de ensino mediado por TDICs.

\begin{tabular}{|c|c|}
\hline Estratégias & Características \\
\hline $\begin{array}{l}\text { Educação presencial } \\
\text { enriquecida com } \\
\text { meios digitais }\end{array}$ & $\begin{array}{l}\text { Os processos de ensino e de aprendizagem (PEA) são desenvolvidos no } \\
\text { mesmo espaço geográfico, com presença física, e enriquecidos por } \\
\text { diferentes dispositivos e tecnologias digitais (TD), as quais podem variar } \\
\text { em frequência e intensidade. Pode envolver dispositivos fixos e móveis, } \\
\text { robótica, wearables, jogos digitais, } Q R C o d e s \text {, dentre outros. }\end{array}$ \\
\hline $\begin{array}{c}\text { Ensino remoto ou } \\
\text { aula remota }\end{array}$ & $\begin{array}{l}\text { Adaptação do ensino presencial físico (mesmas disciplinas, currículo, } \\
\text { metodologias e práticas pedagógicas), que é transposto para os meios } \\
\text { digitais, em rede. O processo é centrado no conteúdo, que é ministrado } \\
\text { pelo mesmo professor da aula presencial física. Comunicação predomi- } \\
\text { nantemente bidirecional, do tipo um para muitos, no qual o professor } \\
\text { protagoniza videoaula ou realiza uma aula expositiva por meio de siste- } \\
\text { mas de web conferência; o foco está nas informações e nas formas de } \\
\text { transmissão dessas informações. }\end{array}$ \\
\hline Ensino a Distância & $\begin{array}{l}\text { Os PEA ocorrem com separação física e, por vezes, temporal, entre es- } \\
\text { tudantes e professores. Comunicação baseada na escrita, sendo a } \\
\text { primeira referência o estudo por correspondência; posteriormente, o } \\
\text { ensino ocorreu via rádio ou televisão, com a oferta de cursos supletivos } \\
\text { a distância, no modelo de teleducação, com aulas via satélite utilizando } \\
\text { kits de materiais impressos. }\end{array}$ \\
\hline $\begin{array}{c}\text { Educação a } \\
\text { Distância (EaD) } \\
\text { ou eLearning }\end{array}$ & $\begin{array}{l}\text { Utiliza as tecnologias da Internet para propiciar um amplo conjunto de } \\
\text { soluções que objetivam servir de suporte para que a aprendizagem } \\
\text { ocorra. Trabalha no sentido da construção do conhecimento - atividade } \\
\text { do sujeito; aprendizagem colaborativa e cooperativa; maior autonomia } \\
\text { dos sujeitos no processo de aprendizagem; desenvolvimento de proces- } \\
\text { so de avaliação continuada e formativa, por meio do uso de "portfolio"; } \\
\text { alto grau de interatividade - utilização de comunicação síncrona e assín- } \\
\text { crona; aumento da tomada de consciência, ampliação da consciência } \\
\text { social e desenvolvimento de uma Inteligência Coletiva. Comunicação e } \\
\text { interação multidirecional, atualização, armazenamento, recuperação, } \\
\text { distribuição e compartilhamento instantâneo da informação; superação } \\
\text { dos limites de tempo e espaço. }\end{array}$ \\
\hline
\end{tabular}

Fonte: Baseado em Moreira e Schlemmer (2020).

\section{$4 \quad$ PLANO PEDAGÓGICO DO CURSO}

O Plano Pedagógico de Curso (PPC) de Engenharia de Alimentos é o documento regimental das ações gerenciais, de organização curricular e de perfil de egresso da graduação, amparado por princípios relacionados à interdisciplinaridade, à integração de atividades teóricas e práticas e à relação entre ensino, pesquisa e extensão. A estrutura curricular é constituída de 3.600 horas, conforme a Tabela 1, planejada para ser cumprida em 11 semestre letivos.

No PPC do curso de Engenharia de Alimentos há previsão para o cumprimento de até $20 \%$ da carga horária com atividades acadêmicas na modalidade de ensino à distância $(E a D)$. Contudo, essa alternativa nunca foi utilizada pelo corpo docente do Instituto de Ciências Agrárias da UFMG, de modo que todas aulas teóricas e práticas são ministradas utilizando a estratégia do ensino presencial a partir de notas escritas ou expostas em 
multimídia, leitura de bibliografia e análise/discussão de situações cotidianas ao engenheiro.

A modalidade prática de ensino presencial está presente nos ciclos básico e profissional com atividades laboratoriais, bem como,com atividades de campo e atividades de estudo de caso.

Nesse contexto, a Pró-reitoria de Graduação da Universidade Federal de Minas Gerais instigou o Colegiado do Curso de Engenharia de Alimentos e o Núcleo Docente Estruturante (NDE), a proporem ações para adaptar o ensino presencial oferecido à estratégia de Ensino Remoto Emergencial.

A oferta de atividades acadêmicas para um período letivo é planejada desde o final período letivo anterior, considerando a alocação de encargos didáticos aos docentes, a definição de horários e salas de aula, dentre outros itens, e inclui a participação de todos os entes participantes do curso. A oferta das atividades acadêmicas de graduação é publicada no Sistema Acadêmico de Graduação (SIGA) para matrícula dos discentes e gestão do curso.

O período letivo 2020/1 da Universidade Federal de Minas Gerais iniciou-se no dia 02 de março de 2020. Em função da disseminação da Covid-19, a UFMG suspendeu suas atividades presenciais em todos os campi no dia 18 de março de 2020.

A Pró-reitoria de Graduação da UFMG iniciou levantamento junto à comunidade acadêmica - unidades administrativas, departamentos, colegiados de curso e entidades representativas - de informações e propostas para a adaptação ao Ensino Remoto Emergencial. Esse levantamento culminou na Resolução do Conselho de Ensino, Pesquisa e Extensão № 02/2020, de 9 de julho de 2020, que dispõe sobre a regulamentação do Ensino Remoto Emergencial para os cursos de graduação da UFMG durante período de pandemia da doença Covid-19. Além disso, a Câmara de Graduação do Conselho de Ensino Pesquisa e Extensão da UFMG, por meio da Resolução CG № 03/2020, elaborou um documento apresentando à comunidade acadêmica: i) diretrizes para o $E R E$; ii) estratégias para adaptação do processo de ensino-aprendizagem; e iii) subsídios para essas reflexões, até que seja possível retomar gradualmente o ensino presencial.

Os colegiados de curso foram responsáveis de adaptar os Planos de Ensino das disciplinas ao ensino remoto, respeitando as diretrizes apresentadas pela UFMG.

\section{METODOLOGIA}

Após a suspensão das atividades presenciais devido à pandemia de Covid-19, e o estabelecimento das diretrizes a serem seguidas na UFMG para adaptação do ensino presencial ao ensino remoto emergencial, o Colegiado do curso de Engenharia de Alimentos consultou seus docentes e discentes por meio de formulários eletrônicos para definir suas ações. Inicialmente, um questionário proposto pela Pró-reitoria de Graduação foi encaminhado aos professores do Instituto de Ciências Agrárias da UFMG que lecionam no curso de Engenharia de Alimentos.

Em seguida, questionários eletrônicos foram encaminhados aos alunos para captar a percepção do corpo discente quanto à adaptação ao Ensino Remoto Emergencial, desde condições de acessibilidade a essa estratégia de ensino, até a expectativa em relação ao ERE. O primeiro questionário foi direcionado aos prováveis formandos e o segundo à totalidade dos alunos.

As respostas foram tratadas e um relatório foi elaborado e encaminhado à administração central da UFMG. Os dados obtidos balizaram as adaptações dos planos de ensino das disciplinas e as ações tomadas pela universidade e pelo colegiado de curso e 
foram importantes para a compreensão dos efeitos da suspensão das atividades presenciais.

No final do período letivo de 2020/1, uma avaliação do ERE foi realizada pelo Colegiado, sob a forma de um questionário eletrônico adaptado enviado aos docentes, discentes e servidores técnico-administrativos.

\section{RESULTADOS}

\subsection{Avaliação Preliminar de Docente}

A pesquisa sobre utilização de dispositivos e acesso à Internet foi realizada entre os dias 20 e 25 de maio de 2020, sendo contemplados 28 docentes de um total de 32 . 0 levantamento constitua das seguintes temáticas: i) as atividades acadêmicas curriculares sob responsabilidade do docente podem, em caráter excepcional, ter suas aulas presenciais substituídas por aulas ou outras atividades didáticas realizadas com o auxílio de meios digitais?; ii) dentre as atividades acadêmicas curriculares pelas quais o docente é responsável existem aquelas para as quais não há condições de serem auxiliadas por meios digitais?; iii) diante da necessidade de um distanciamento mínimo de segurança entre os estudantes nos espaços onde as aulas presenciais são ministradas, as atividades acadêmicas curriculares sob responsabilidade do docente podem ter suas aulas ofertadas utilizando uma estratégia de rodízio?; e iv) como o docente avalia as suas condições de acesso e domínio das ferramentas computacionais e práticas pedagógicas que futilizam de tecnologias digitais e de atividades didáticas com acompanhamento remoto?

Os resultados mostram que $87,5 \%$ dos docentes participaram do levantamento. Dos docentes respondentes, $89,3 \%$ indicaram que as atividades acadêmicas poderiam ser ofertadas de modo remoto; $64 \%$ responderam que poderiam adotar uma estratégia de rodízio, caso fosse necessário. Quanto às condições de acesso e ao domínio das ferramentas computacionais para a utilização de metodologias de ensino remotas, 10,7\% avaliaram como excelente, 35,7 \% como bom, 35,7 \% como razoável e 17,9\% como ruim, conforme apresentado na Figura 1. A maioria dos professores manifestaram preocupação com a falta de treinamento com ferramentas do ensino remoto e com a infraestrutura física necessária para o ensino remoto, considerando a execução a partir das residências, em função da necessidade do isolamento social e da suspensão das atividades presenciais na UFMG.

Figura 1 - Resposta dos docentes quanto as condições de acesso e domínios as TDICs.

Como você avalia as suas condições de acesso e dominio a ferramentas computacionais e práticas pedagógicas que fazem uso de tecnolog...ividades didáticas com acompanhamento remoto? 28 respostas

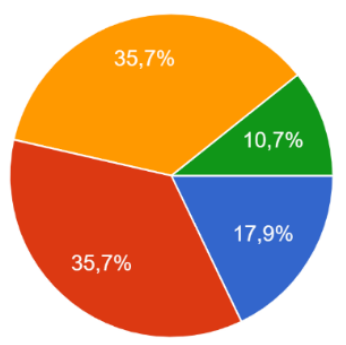

Fonte: Autores 


\subsection{Avaliação Preliminar de Discente}

O Colegiado do curso de Engenharia de Alimentos realizou, entre os dias 20 a 30 de maio de 2020, a pesquisa com os alunos para a avaliação da percepção das condições de realização de atividades remotas. O levantamento foi realizado por meio de formulário eletrônico, amplamente divulgado nas mídias sociais e pelo e-mail institucional do aluno.

O levantamento foi dividido em dois questionários: o primeiro para avaliar as necessidades acadêmicas para os discentes com previsão de formatura para o ano de 2020, com o intuito de compreender quais ações deveriam ser tomadas pela universidade para contornar a necessidade de isolamento social que se apresentava.

O objetivo principal da consulta aos prováveis formandos foi identificar as atividades acadêmicas que necessitavam ser oferecidas para que a integralização dos créditos desses alunos pudesse ser realizada de acordo com o Plano Pedagógico do Curso. Foram identificados 22 alunos em 168 com condições de colar grau em 2020. Desse total de 22, 81,8 \% não haviam cursado a disciplina de Trabalho de Conclusão de Curso; 72,7\% já haviam integralizado toda a carga horária obrigatória, 59,1\% toda a carga horária optativa e $68,2 \%$ toda a carga horária de formação livre. Quanto ao estágio curricular, 86,4\% não haviam cursado a disciplina e 54,0\% estavam tendo dificuldade para encontrar estágio em virtude da pandemia de Covid-19.

As grandes dificuldades encontradas pelo levantamento foram em relação ao término dos Trabalhos de Conclusão de Curso e à prática de estágios. Tanto para os TCC, quanto para os estágios, foi sugerido aos docentes que orientassem seus alunos prioritariamente em trabalhos teóricos de revisão e, na impossibilidade desse recurso, a UFMG possibilitou a presença em laboratório de forma segura e mantendo as orientações sanitárias. A UFMG criou grupo de biossegurança para orientar trabalhos presenciais essenciais no seu interior. Em relação aos estágios, alguns alunos conseguiram realizar a atividade presencialmente nas empresas, já que o ramo alimentício é uma atividade essencial e permaneceu em atividade. Porém, algumas empresas não receberam estagiários durante esse período.

O segundo questionário foi enviado à totalidade dos alunos e teve como objetivos fazer um levantamento socioeconômico dos discentes e construir um retrato das condições de acessibilidade ao ensino remoto pelos alunos do curso de Engenharia de Alimentos. Também foi objeto de análise o levantamento de quais alunos com necessidades especiais precisariam de maior atenção do colegiado para terem acesso ao ERE.

Dos 168 discentes do curso, 154 responderam ao questionário, ou seja, 91,7 \%. Dos 14 alunos não respondentes, 6 são alunos ingressantes e 8 são matriculados nos demais períodos.

Apenas $33,1 \%$ dos discentes não recebem algum apoio financeiro da UFMG ou da Fundação Mendes Pimentel, na forma de bolsa de ensino, pesquisa, extensão ou auxílio financeiro. Constatou-se que $85,1 \%$ dos alunos estavam residindo com o seu núcleo familiar, durante o período de pandemia, mas apenas $40 \%$ dos estavam residindo na cidade de Montes Claros, o que dificultava a estratégia de rodízio para aulas presenciais. $65,6 \%$ das famílias de estudantes receberam o auxílio emergencial do governo federal e outros $16,2 \%$ tentaram e não conseguiram, evidenciando que quase $80,0 \%$ das famílias de estudantes vivem com renda menor que 3 salários-mínimos. Esses resultados estão apresentados na Figura 2. 
Quanto ao acesso ao ensino remoto pelos alunos, tanto no que se refere à infraestrutura física, tais como, computadores, notebooks, celulares, quanto ao acesso ao ambiente virtual, via Internet, os resultados mostraram que, dos 154 alunos respondentes, $74 \%$ afirmaram ter a estrutura necessária, incluindo equipamentos e acesso à Internet. Além disso, 67,5\% dos alunos respondentes afirmaram não ter necessidade de compartilhar equipamentos para participar de ensino remoto. Como $26 \%$ dos discentes alegaram não ter estrutura para o ensino remoto, políticas de apoio foram implantadas para financiar a compra de equipamento e/ou a disponibilização de acesso à Internet.

Figura 2 - Resposta dos docentes quanto as condições de socioeconômicas dos discentes.

Você recebe algum tipo de auxilio financeiro da UFMG ou FUMP?

154 respostas
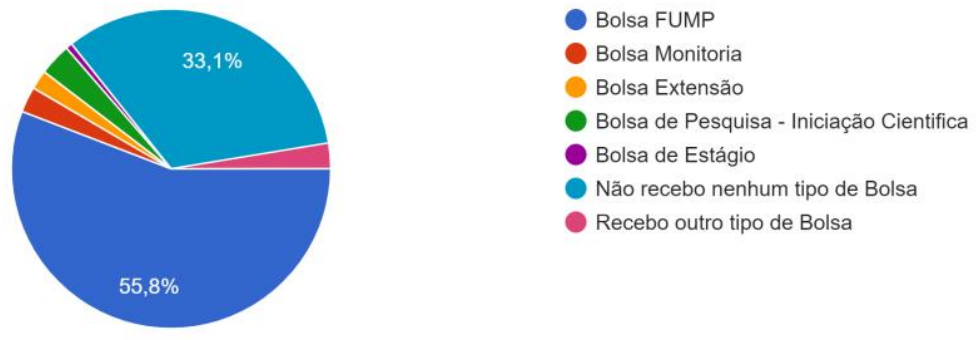

Recebo outro tipo de Bolsa

Você e/ou núcleo familiar estão recebendo o auxilio emergencial do governo? 154 respostas
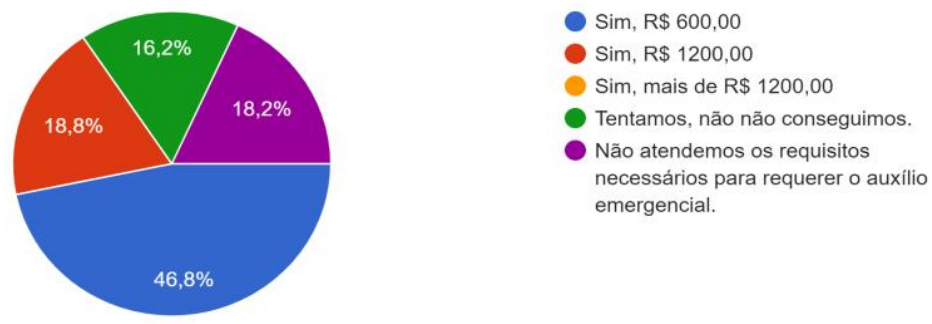

Fonte: Autores

\subsection{Monitoramento e Avaliação do ERE}

O período letivo 2020/1 foi ofertado de forma remota emergencial, conforme a Tabela 01.

Tabela 1 - ANO 2020 - 1o período letivo de 2020.

\begin{tabular}{l|l}
\hline 02/03/2020 & Início do 1o Período letivo de 2020 (2020/1). \\
\hline $18 / 03 / 2020$ & $\begin{array}{l}\text { Suspensão das aulas presenciais dos cursos de Gradua- } \\
\text { ção nos campi da UFMG }\end{array}$ \\
\hline $03 / 08 / 2020$ & Reinício do 1o período letivo de 2020 (2020/1). ERE \\
\hline $07 / 11 / 2020$ & Término do 1o período letivo de 2020 (2020/1). ERE \\
\hline
\end{tabular}

Após o término do período letivo, nova pesquisa foi realizada com discentes e docentes para monitorar e avaliar a implementação do Ensino Remoto Emergencial UFMG. Dos 166 alunos matriculados e dos 24 docentes ofertantes de disciplinas, 70 discentes e 
16 professores responderam ao levantamento, respectivamente. Segundo o PPC do curso, existem 56 disciplinas obrigatórias e 31 optativas, das quais 38 foram ofertadas no período 2020/1, sendo 09 teóricas, 04 práticas e 25 teórico/práticas.

A operacionalização do Ensino Remoto Emergencial no âmbito do curso de graduação em Engenharia de Alimentos da UFMG foi avaliada junto a docentes, discentes e técnicos-administrativos em quatro dimensões, a saber: a) boas práticas identificadas no processo de implementação do ERE; b) dificuldades no processo de implementação do ERE; c) demandas no processo de implementação do ERE; e d) satisfação no processo de implementação do ERE.

Destacam-se entre as boas práticas identificadas: a utilização de videoaulas na plataforma YouTube; a gravação de aulas com a imagem do professor; as aulas síncronas mais sintetizadas e breves, alinhadas à realidade do ERE; a alternância entre atividades síncronas e assíncronas; os grupos e a interação pelo WhatsApp, as reuniões para compartilhamento de experiências e apoio do programa de tutoria do curso de Engenharia de Alimentos.

Dentre as dificuldades, destacam-se a baixa frequência e participação em atividades síncronas; a dificuldade em utilizar certas ferramentas por parte de docentes e alunos; a maior demanda de tempo e esforço no preparo de material, a dificuldade de acesso a referências bibliográficas e biblioteca, os problemas de conexão; a ausência de presença física, que dificulta processo de interação e aprendizagem no ERE.

A partir das respostas obtidas nos questionários enviados aos docentes e discentes, é possível observar que, de um modo geral, o nível de satisfação com o ERE encontra-se acima de $44 \%$. Todavia, observa-se, ainda, que quase $20 \%$ dos docentes manifestam algum grau de insatisfação, conforme as Figura 3 e 4.

Figura 3 - Resposta dos docentes quanto ao grau de satisfação na implantação do ERE

Qual o seu grau de satisfação no processo de implementação do Ensino Remoto Emergencial. 16 respostas

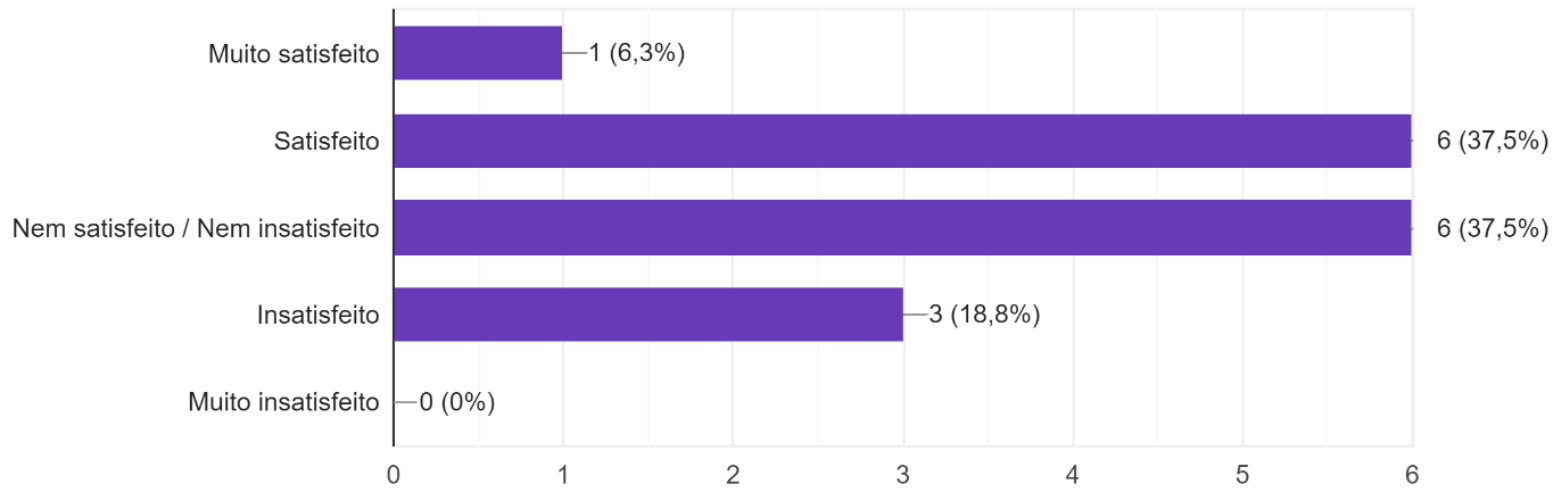

Fonte: Autores 
Figura 4 - Resposta dos docentes quanto ao grau de satisfação na implantação do ERE

Qual o seu grau de satisfação no processo de implementação do Ensino Remoto Emergencial. 70 respostas

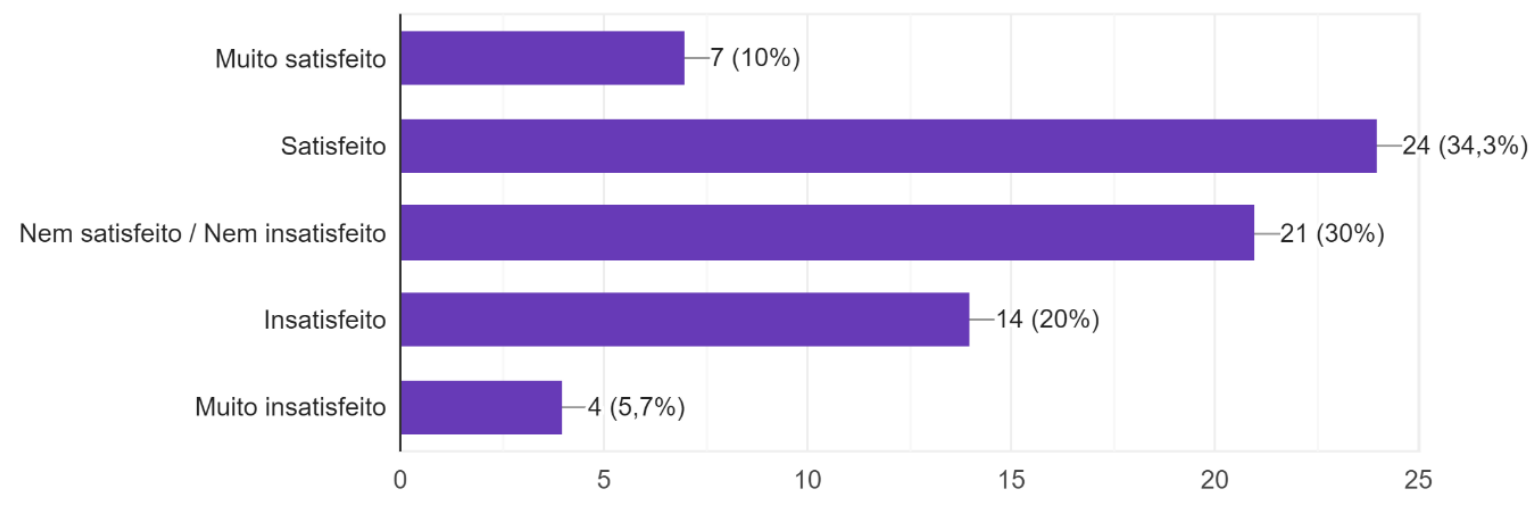

Fonte: Autores

\section{CONCLUSÕES}

Fruto do esforço coletivo e individual de docentes e alunos, a operacionalização do ERE no curso de Engenharia de Alimentos representa uma experiência, até o momento, bem-sucedida. Evidentemente, ajustes estão e deverão ser realizados, tendo em vista a finalização do semestre, de modo a minimizar os possíveis prejuízos ao processo de formação e ensino, principalmente no que se refere ao acesso à rede de bibliotecas on-line e ao pleno entendimento da resolução 002/2020 CEPE, pois o não cumprimento das normas causa impasses nas relações alunos/professores.

\section{AGRADECIMENTOS}

O presente trabalho foi realizado com apoio do Núcleo Docente Estruturante e do Colegiado do curso de Engenharia de Alimentos da Universidade Federal de Minas Gerais. Agradecemos à Pró-reitoria de Graduação da UFMG pelo apoio nas ações de implementação do Ensino Remoto Emergencial.

\section{REFERÊNCIAS}

ARRUDA, E.P. Educação Remota Emergencial: elementos para políticas públicas na educação brasileira em tempos de Covid-19. Em Rede - Revista de Educação a Distância, v. 7, n. 1, p. 257-275, 2020. Disponível em: https://www.aunirede.org.br/revista/index.php/emrede/article/view/621. Acesso em 03 de maio de 2020.

BARBOSA, A.M.; VIEGAS, M.A.S. BATISTA, R.L.N.F.F. Aulas presenciais em tempos de pandemia: relatos de experiências de professores do nível superior sobre as aulas remotas. Revista Augustus, v. 25, n. 51, p. 255-280, 2020. Disponível em: https://revistas.unisuam.edu.br/index.php/revistaaugustus/article/view/565/302 Acesso em 04 de maio de 2020.

BRASIL. Ministério da Educação. Portaria № 343, de 17 de março de 2020: Dispõe sobre a substituição das aulas presenciais por aulas em meios digitais enquanto durar a situação 
de pandemia do Novo Coronavírus - COVID-19. Disponível em: https://www.in.gov.br/en/web/dou/-/portaria-n-343-de-17-de-marco-de-2020-248564376 Acesso em 03 de maio de 2020.

UFMG. "Ensino Remoto Emergencial (ERE) nos cursos de graduação da UFMG. Diretrizes para o ensino remoto. Disponível em: https://www2.ufmg.br/prograd/prograd/Pro-Reitoriade-Graduacao/Publicacoes/Ensino-Remoto-Emergencial. Acesso em 08 de maio de 2020.

HODGES, C.; MOORE, S.; LOCKEE.; TRUST, T.; BOND, A. The difference between emergency remote teaching and online learning. EDUCAUSE Review. Louisville, CO, March 27, 2020. Disponível em: https://er.educause.edu/articles/2020/3/the-differencebetween-emergency-remote-teaching-and-online-learning. Acesso em 06 de maio de 2020.

MOREIRA, J.A.; SCHLEMMER, E. Por um novo conceito e paradigma de educação digital onlife. Revista UFG, v. 20, n. 63438, p. 1-35, 2020. https://www.revistas.ufg.br/revistaufg/article/view/63438/34772. Acesso em 06 de maio de 2020.

MABRITO, M. A study of synchronous versus asynchronous collaboration in an online business writing class. The American Journal of Distance Education, v. 20, n. 2, p. 93-107, 2006. Disponível em: https://doi.org/10.1207/s15389286ajde2002 4. Acesso em 06 de maio de 2020.

\title{
EMERGENCY REMOTE EDUCATION: THE CASE OF FOOD ENGINEERING COURSE AT THE FEDERAL UNIVERSITY OF MINAS GERAIS
}

\begin{abstract}
:
In the context of the Covid-19 pandemic, Emergency Remote Education (ERE) presented itself as a concrete possibility to guarantee the continuity of the teaching-learning process for students of UFMG undergraduate courses. The temporary suspension of faceto-face classes at universities was adopted with the aim of mitigating the spread of the coronavirus and reducing the risk of contagion and proliferation among teachers and students.

This paper presents the experience of the Collegiate of the Food Engineering course in adapting face-to-face teaching to remote emergency teaching, from planning, adapting the subjects' teaching plans to Remote Emergency Teaching and its implementation. An evaluation survey of the implementation of the ERE was carried out to evaluate the different activities in the course.
\end{abstract}

Keywords: Emergency Remote Education, COVID-19 Pandemic, Management, Diagnostic 